DIW BERLIN

Discussion Papers

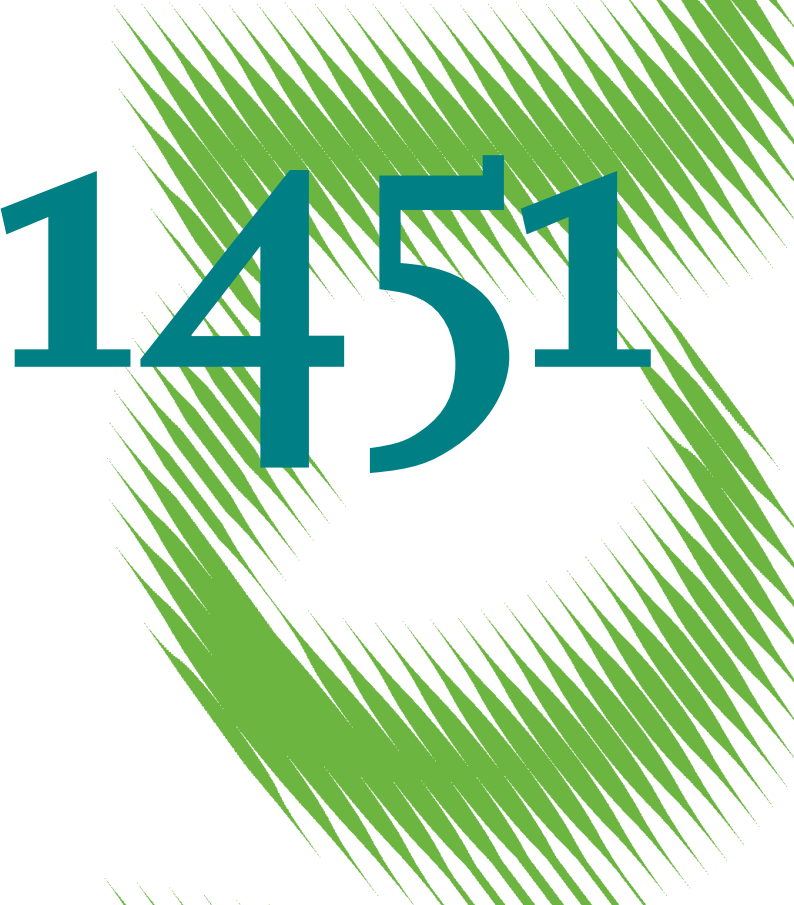

Two Price Zones for the German Electricity Market Market Implications and Distributional Effects 
Opinions expressed in this paper are those of the author(s) and do not necessarily reflect views of the institute.

IMPRESSUM

(C) DIW Berlin, 2015

DIW Berlin

German Institute for Economic Research

Mohrenstr. 58

10117 Berlin

Tel. +49 (30) $89789-0$

Fax +49 (30) $89789-200$

http://www.diw.de

ISSN electronic edition 1619-4535

Papers can be downloaded free of charge from the DIW Berlin website:

http://www.diw.de/discussionpapers

Discussion Papers of DIW Berlin are indexed in RePEc and SSRN:

http://ideas.repec.org/s/diw/diwwpp.html

http://www.ssrn.com/link/DIW-Berlin-German-Inst-Econ-Res.html 


\title{
Two Price Zones for the German Electricity Market - Market Implications and Distributional Effects
}

\author{
Jonas Egerer $^{\mathrm{a}, \mathrm{b}, *}$, Jens Weibezahn $^{\mathrm{b}}$, Hauke Hermann $^{\mathrm{c}}$ \\ ${ }^{a}$ DIW Berlin, Department of Energy, Transportation, Environment, Mohrenstraße 58, 10117 Berlin, Germany \\ ${ }^{b}$ Technische Universität Berlin, Workgroup for Infrastructure Policy (WIP), Straße des 17. Juni 135, 10623 Berlin \\ ${ }^{c}$ Oeko-Institut e.V., Schicklerstraße 5-7, 10179 Berlin
}

\begin{abstract}
We discuss the implications of two price zones, i.e. one northern and southern bidding area, on the German electricity market. In the northern zone, continuous capacity additions with low variable costs cause large regional supply surpluses in the market dispatch while conventional capacity decreases in the southern zone. As the spatial imbalance of supply and load is increasing, the current single bidding area results more often in technically infeasible market results requiring curative congestion management.

There is an ongoing discussion about the potential effects of introducing bidding zones in Germany. Using a line sharp electricity sector model, this paper analyzes the system implications and the distributional effects of two bidding zones in the German electricity system in 2012 and 2015, respectively. Results show a modest decrease in cross-zonal re-dispatch levels, in particular in 2015. However, overall network congestion and re-dispatch levels increase in 2015 and also remain high for both bidding zones. Results are very sensitive to additional line investments illustrating the challenge to define stable price zones in a dynamic setting. With two bidding areas, prices in the model results increase in the southern zone and decrease in the northern zone. The average price deviation grows from 0.4 EUR/MWh in 2012 to $1.7 \mathrm{EUR} / \mathrm{MWh}$ in 2015 with absolute values being significantly higher in hours with price differences. Stakeholders within zones are exposed to the price deviations to a different extent. Distributional effects are surprisingly small compared to the wholesale price or different network charges.
\end{abstract}

Keywords: German electricity market, congestion management, bidding zone configuration, distributional effects.

JEL: L51, L94, Q41, Q48

\section{Introduction}

In liberalized energy-only markets, the marginal pricing scheme is a well-established approach for determinating power plant dispatch in spot markets. However, market dispatch can be technically infeasible if the market neglects the spatial location of supply and load as well as physical constraints in the transmission network. Curative congestion management - mainly re-dispatch of the market result - becomes necessary, thus adding to the price of electricity. Locational price signals could reduce required adjustments of the initial market dispatch. Possible options include adjustments of the existing bidding zone configuration by re-shaping existing and introducing additional zones (i.e. zonal pricing with alternative bidding zones) or a shift to a nodal market resolution at the level of the individual network nodes of the high-voltage transmission system (i.e. nodal pricing).

\footnotetext{
${ }^{*}$ Corresponding author

Email address: jegerer@diw.de (Jonas Egerer)
} 
Market liberalization in Europe was initiated by European legislation (European Commission, 1996, 2003, 2009) but it is implemented through national regulation. This process mostly resulted in national bidding zones with no additional regional price signals. ${ }^{1}$ In this context, the development of the Internal Energy Market has coupled bidding zones, implicitly auctioning net transfer capacities (NTCs) between them. Compared to nodal pricing with its market integration of line specific network capacities, the zonal representation defines larger bidding areas while aggregating internal and cross-zonal network constraints to NTCs with neighboring bidding zones. Preventive congestion management is possible to some extent with the calculation of the cross-zonal NTCs. Still, market dispatch can be infeasible in the physical transmission system, requiring curative congestion management, mainly re-dispatch measures.

The mostly national bidding zones in effect, as of 2015, are under scrutiny at the European level with new guidelines on the way (European Commission, 2014) that will address network security, overall market efficiency, as well as stability and robustness as criteria for reviewing the bidding zone configuration. Such a review could affect the large German-Austrian bidding zone in central Europe.

Before the low carbon transformation of the German electricity sector was initiated, the system was dominated by conventional plants close to load centers. The only major regional imbalance had been, for historic reasons, the surplus in lignite capacity in eastern Germany. Regional price signals were not relevant when market liberalization was initiated as the least cost national market dispatch could be implemented with the existing physical transmission system. Within the last decade, the German electricity system has been undergoing a transformation, increasing regional imbalances between supply and load: eight nuclear power plant blocks have been phased out in 2011 and the capacity of variable renewable generation has increased. ${ }^{2}$ Except for a few remaining nuclear power plants, most of the conventional power plants with the lowest variable costs - nuclear and lignite, followed by modern hard coal plants recently built or under construction - are located in northern Germany. ${ }^{3}$ Thus, although there is not a shortage in conventional capacity in southern Germany, the regional share of capacity in the least cost dispatch is not in balance with the regional load distribution (Kunz et al., 2013). Consequently, limited north-south transmission capacity triggers a physically infeasible market dispatch in an increasing number of hours, characterized by low load and/or high wind feed-in. Due to this, re-dispatch costs have increased from only $25 \mathrm{mn}$ EUR/year in 2009 (BNetzA, 2010) to $165 \mathrm{mn}$ EUR/year in 2012 (BNetzA and Bundeskartellamt, 2014). The regional imbalance in supply will increase with the nuclear phase-out and added capacity of new coal power plants and wind power in northern Germany. These circumstances provide possible arguments for the idea of splitting the single German bidding zone into one northern and one southern zone. ${ }^{4}$

This discussion increasingly attracts attention in Germany (Wissenschaftlicher Beirat BMWi, 2014; Bettzüge, 2014; Frontier Economics and Consentec, 2011, 2013; Monopolkommission, 2011) and in Europe (ACER, 2014; Thema, 2013; ČEPS et al., 2012). ${ }^{5}$ The question is how to adapt markets with increasing regional imbalances. The current measure of choice to retain the single electricity price in Germany is network expansion as suggested by the German grid development plan (50Hertz et al., 2012) and the Federal Ministry for Economic Affairs and Energy (BMWi, 2014). Still, most of the approved investment projects will require many years to be completed while the nuclear phase-out will be completed in 2022. Large capacities of on- and offshore wind power will add to the regional imbalance. Regional investments in back-up capacity as replacement for nuclear power plants in southern Germany also affect market dispatch. In the current uniform pricing scheme, the proposed gas-fired power plants will not relieve the regional imbalance.

\footnotetext{
${ }^{1}$ Exceptions are Norway, Sweden, Denmark, and Italy with multiple bidding zones at the national level and a joint bidding zone for Germany and Austria.

${ }^{2}$ The share of renewable generation in the German electricity market reached $22.1 \%$ in 2012 , including $8.1 \%$ wind and $4.2 \%$ photovoltaic (AG Energiebilanzen e. V., 2013). The installed capacity has been about $35 \%$ of peak demand for each technology.

${ }^{3}$ The border between northern and southern Germany depends on the context. In this paper, the regions are split with oversupply of electricity in the north and the center while a deficit exists in the south. It is confined by the border triangle of Germany, Belgium, and Luxemburg at the western edge to Frankfurt and the northern border of Bavaria. Thus, the southern zone includes the states of Baden-Wuerttemberg, Bavaria, the Saarland, and parts of Rhineland-Palatinate, as well as Hesse.

${ }^{4}$ This paper does not consider the implications on the Austrian electricity system, which is currently part of the existing one bidding zone with Germany.

${ }^{5}$ From a European perspective additional arguments are mentioned, e.g. loop-flows in neighboring countries not represented by the current market results.
} 
Considering current $\mathrm{CO}_{2}$ and fuel prices, their variable generation costs are higher than those for coal-fired plants in the northern zone. A rather short-term alternative is the implementation of two bidding zones. However, one consequence are effects on the market result and redistribution between stakeholders. While many aspects are of relevance for the decision at the level of spatial market aggregation, distributional effects on market participants are of particular importance for moving from one scheme to another (Löschel et al., 2013; ACER, 2014).

Bidding zones require the integration of a cross-zonal NTC capacity in the market and result in market splitting and diverging electricity prices within Germany in hours the NTC capacity becomes a binding constraint. ${ }^{6}$ Consequently, the geographic scope of bidding zones and NTC levels auctioned into the market are the relevant parameters determining the effectiveness of zonal price differentiation as well as zonal gains and losses of stakeholders in the market. Applying an electricity sector model, this paper elaborates on such a change in the congestion management for 2012 and 2015 scenarios, including one scenario with network extension, and quantifies different effects. Among them are re-dispatch levels as well as distributional effects for consumers and producers in the two price zones. ${ }^{7}$

The remainder of the paper is structured as follows: Section 2 reviews the relevant literature on the discussion of zonal and nodal pricing. Section 3 introduces the two consecutive model stages of the spot market dispatch and the re-dispatch adjustments. Section 4 presents and discusses the model results for two bidding zones in the German electricity system. The last section summarizes the numeric analysis and concludes with policy implications.

\section{Literature Overview}

Compared to zonal pricing in Europe, some markets have implemented a nodal pricing scheme. ${ }^{8}$ Nodal pricing is often considered as a benchmark for efficient congestion management. It allows for transmission pricing by considering loop-flows and line specific congestion in the market (Hogan, 1992, 1997; Stoft, 1997). Market dispatch does not require congestion management measures under perfect foresight. Brunekreeft et al. (2005) and Rubio-Oderiz and Perez-Arriaga (2000) suggest that nodal pricing (and complementary capacity charges) also signals the efficient location of generation investment. However, nodal markets increase complexity (e.g. several hundred nodes in Germany) and raise questions of market liquidity. In the European debate on the configuration of bidding zones, nodal pricing does currently not rank high on the agenda.

Ehrenmann and Smeers (2005) discuss different zonal congestion management schemes that have been in the discussion for European congestion management schemes during that time. Assuming that certain identifiable structural bottlenecks exist within the network, bidding zones adjusted according to the lines in question result in a more efficient dispatch. Yet, an aggregation of several cross-border lines between zones imposes new issues when loop-flows are considered.

Hogan (1999) points out the shortfalls of a zonal market design compared to nodal pricing. A zonal representation gives the impression that different locations are similar in their pricing, providing wrong pricing information for market participants under some circumstances. Internal congestion with a high and - due to loop-flows - not always directly comprehensible effect on the electricity network is not visible and the market dispatch therefore becomes less transparent. At the same time market rules have to be more complex in order to reflect the physical constraints of the transmission system within bidding zones not considered in the market dispatch (i.e. re-dispatch measures). Identical prices at different nodes would already show in a nodal layout, obviating the need for a zonal pooling of nodes. Furthermore, the more

\footnotetext{
${ }^{6}$ This paper is limited to a short-term analysis of the spot market and neglects dynamic adjustments of market participants, e.g. by investments in power plants due to more volatile regional prices, change in regional load levels, and possible issues with local market power of generation companies.

${ }^{7}$ This paper focuses on the German discussion and abstracts from system and distributional implications on European level. The model scope is limited to the German electricity sector.

${ }^{8}$ The most prominent example is the PJM interconnection in the northeastern part of the US.
} 
transparent nature of a nodal market reduces market power since generators could not use their knowledge of physical constraints in a bidding zone in their own favor.

Neuhoff et al. (2011) discuss additional options for congestion management in European power networks. They point out that only LMP has the potential to achieve full market integration. Zonal pricing is described as a less complex design, yet problems arise from the optimal configuration of possible bidding zones. While this design matches quite well with the less complex transmission system in the Nordic countries, it is less useful for the highly meshed continental European system since congested lines are difficult to identify as they tend to change constantly. Experiences from the U.S. markets show similar problems.

Supponen (2011), on the other hand, argues in favor of splitting Europe in further bidding zones better reflecting congestion in the network within countries in order to improve investment signals for (interconnector) transmission capacity. Using a six-node demonstration network, Oggioni and Smeers (2013) show that the configuration of bidding zones and especially the determination of NTCs between the zones are crucial for the efficiency of a zonal pricing design, like the European market coupling. Burstedde (2012) analyzes potential bidding zones for the European electricity market. The paper clusters nodes in the network by locational marginal prices using cluster analysis. Dispatch, re-dispatch, and total system costs are calculated for different zone configurations. A nodal pricing model serves as benchmark. Results show that a zonal market configuration only leads to a small increase of total system cost compared to nodal pricing. With the right choice of NTCs to represent scarcity signals for transmission a better ex-ante market dispatch is reached and less requirements for re-dispatch occur. Breuer et al. (2013) and Breuer and Moser (2014) use a similar methodology for the delimitation of bidding zones. Clustering nodes with similar prices to a different number of zones they find that about 14 zones for Europe would be optimal regarding the trade-off between network security and market efficiency, on the one hand, and the stability of bidding zone delimitation, on the other hand. Due to the ever changing nature of the electricity system with the ongoing commissioning and decommissioning of plants and lines, the delimitation of zones should change frequently, which does not favor market participants.

Holmberg and Lazarczyk (2015) compare the efficiency of three existing market designs in electricity markets: nodal, zonal, and discriminatory pricing (pay-as-bid). They conclude that all three designs lead to the same efficient dispatch but with zonal pricing generators receive additional payments from system operators. Frontier Economics and Consentec (2011, 2013), on the other hand, raise concerns about some issues connected to the reconfiguration of existing bidding zones in the European market coupling regime. The configuration of bidding zones must account for possible illiquidity and issues of market power in smaller zones. The possibility of a regular reassessment of bidding zones threatens a stable and predictable investment climate. Bjørndal et al. (2003) also find the possibility of exercising market power. In addition, they show that a zonal design for the Nordic power market leads to completely different results regarding price, flows, congestion, and social surplus compared to a nodal approach.

Wawer (2007) points out that zonal pricing is a possible option for Germany, since EEX rules already in place state that in case of congestion between control areas separate auctions for each zone can be instated. When re-dispatch costs increase, a zonal market design should be introduced. Weigt et al. (2010) and Nüßler (2012) show that with the rising necessity for re-dispatch, useful counter measures are either a HVDC overlay from north to south (a grid extension contained in part in the German network extension plan) and/or a change in market design towards regionally differentiated prices like with zonal pricing. Nüßler (2012), Trepper et al. (2013), and Kunz (2013) examine the German power system in regard to the spot market and re-dispatch with a further increased congestion situation. However, while Nuessler and Kunz only focus on uniform pricing and sensitivity analyses, Trepper et al. analyze price zones, aggregating nodes to 21 buses for the the German system.

This paper extends the existing literature by a discussion on zonal pricing in Germany examining the system and distributional effects of two proposed price zones with a nodal re-dispatch model. 


\section{Spot Market and Re-dispatch Model}

This paper applies a bottom-up electricity sector model, separately optimizing the two consecutive steps of market settling in the spot market and for re-dispatch by the TSO. ${ }^{9}$ One bidding area with a single hourly price for all of Germany is compared to a market design with two bidding zones. In the first step, the spot market model determines a cost-minimizing market dispatch. Thereby, electricity generation and cross-zonal trade have to settle the load in all bidding zones. The zonal market results, only considering aggregated information on spatial network constraints, might prove technically infeasible for physical realization in the transmission network. Thus, in a second step, the re-dispatch model calculates cost-minimizing adjustments to the initial market dispatch. This represents actions by the TSO, altering generation levels for individual power plants until transmission flows are within the technical specifications for every transmission line. ${ }^{10}$ Thus, generation levels of the spot market model are used as exogenous default and the transmission system is modeled using the DC load flow approach (Schweppe et al., 1988). The model formulation builds on the ELMOD framework (Leuthold et al., 2012) and includes a re-dispatch model (Breuer et al., 2011; Kunz, 2013). ${ }^{11}$ The methodology is applied on the case of one and two bidding zones using a detailed spatial data set of the German electricity system (Egerer et al., 2014).

\subsection{Spot market model}

Both cases, with either one or two price zones, have the same cost minimizing objective function for variable generation costs of conventional power plant blocks (eq. 1). Variable generation costs $(C)$ calculate by fuel prices, carbon emission factors, as well as carbon prices and the efficiency factor. The constraints include the limitation of the generation output for every power plant block (eq. 2a), hourly restrictions for nodal renewable output per technology at zero variable costs (eq. 2b), and the representation of pumpedstorage plants with a cycle efficiency of $75 \%$ (eqs. 2c, 2d, 2e). The spatial scope of the energy balance deviates with the size of the bidding zones in the market. All data is available on a nodal network level and aggregates to the price zones. For this application the spot market model optimizes power plant operation in weekly blocks of 168 hours. ${ }^{12}$

$$
\min _{g, r, p s} \operatorname{costs}^{s p}=\sum_{p, t}\left(g_{p, t} C_{p, t}\right)
$$

$$
\begin{aligned}
g_{p, t} & \leq \bar{G}_{p, t} \\
r_{n, s, t} & \leq \bar{R}_{n, s, t} \\
\text { pslevel } & =0.75 \overleftarrow{p s}_{e, t}-\overrightarrow{p s}_{e, t}+\text { pslevel }_{e, t-1} \\
\overrightarrow{p s}_{e, t}+\overleftarrow{p s}_{e, t} & \leq \overline{P S}_{e} \\
\text { pslevel } & \leq \overline{L S}_{e, t}
\end{aligned}
$$

$\forall p, t$

$\forall n, s, t$

$\forall \quad e, t$

$\forall \quad e, t$

$\forall \quad e, t$

As of 2014, the single bidding area with one electricity price for Germany does not value internal network constraints in the market prices. The market dispatch includes the least cost generation capacities of the

\footnotetext{
${ }^{9}$ The model assumes perfect competition and abstracts from uncertainty, load changing costs, minimum operation levels, partial load efficiency factors, and must-run conditions of thermal power plants. These simplifications likely overestimate the system flexibility, both for the spot market model and for re-dispatch.

${ }^{10}$ The model only considers re-dispatch required to prevent network flows exceeding the thermal limits of transmission lines. Other causes of re-dispatch (e.g. regional voltage stability) are not included.

${ }^{11}$ Appendix 1 (table 6) lists all model indices and sets, variables, and parameters.

${ }^{12}$ In the weekly runs hydro pumped-storage plants have inter-hourly constraints. The model optimizes the operation over the course of 168 hours. This allows the weekly load pattern and hourly renewable generation levels to be reflected. The storage level is fixed to zero in the first and last hour of the week (i.e. Friday to Saturday at midnight) to account for the connection of the weekly model runs.
} 
merit order covering the hourly load level. In the model, the single bidding zone is represented by a single energy balance (eq. 3) including all generation $(g, r, \overrightarrow{p s})$, fixed cross-border flows for imports and exports $(I M, E X)$, as well as load $(Q, \overleftarrow{p s})$ in each hour. The marginal on this constraint is the hourly market price in the spot market. The case with two bidding zones allows for deviation form zonal prices in the spot market. Each bidding zone has its own energy balance (eq. 4a) and zonal exchange flows $(z f)$ are limited by the NTC (eq. 4b). The NTC is an aggregated zone to zone trade capacity in the spot market and does not specify the physical path of electricity flows as the DC load flow approach does. In case the constraint on the trade capacity becomes binding in one hour, the marginal power plants and thus the zonal market prices differ between the two zones. The optimal level of the NTC is difficult to determine. In practice it would be determined by the TSO. Based on the circumstances (load, renewable production, etc.) the NTC is adjusted regularly but there is no common algorithm that allows a transparent and comprehensible calculation. It is typically lower than physical line capacity between two zones to account for intra-zonal congestion and other externalities. This application assumes fixed NTC values and tests all levels between 6000 and 10000 MW in steps of 1000 MW between the two bidding zones in Germany.

$$
\begin{gathered}
\sum_{p} g_{p, t}+\sum_{n}\left(\sum_{s} r_{n, s, t}-Q_{n, t}+I M_{n, t}-E X_{n, t}\right)+\sum_{e}\left(\overrightarrow{p s}_{e, t}-\overleftarrow{p s}_{e, t}\right)=0 \quad \forall \quad t \\
\sum_{p \in z} g_{p, t}+\sum_{n \in z}\left(\sum_{s} r_{n, s, t}-Q_{n, t}+I M_{n, t}-E X_{n, t}\right) \\
+\sum_{e \in z}\left(\overrightarrow{p s}_{e, t}-\overleftarrow{p s}_{e, t}\right)+\sum_{y} z f_{z, y, t}=0 \\
\left|z f_{z, y, t}\right| \leq \overline{N T C}_{z, y} \\
z, t
\end{gathered}
$$

\subsection{Re-dispatch model}

The second model stage applies the re-dispatch model to the results of the spot market. It adjusts the market dispatch wherever it is not feasible in the physical transmission network. Technical feasibility is reached by re-dispatch, i.e. decreasing output of some power plants and increasing output for other power plants until the dispatch fulfills every single line constraint in the high-voltage transmission network. The redispatch is not organized in a market but conducted by the TSO with the objective of minimizing generation costs (eq. 5). Increasing the output of conventional generation $\left(g^{+}\right)$causes variable generation costs. On the other hand, decreasing generation levels $\left(g^{-}\right)$for power plants saves variable costs. Typically, system costs increase as power plants initially not in the market dispatch replace power plants with lower variable generation costs initially dispatched. This formulation does not restrict cross-border re-dispatch between the two bidding zones. It assumes that the TSO continues to optimize the joint re-dispatch on the national level.

$$
\min _{g^{+}, g^{-}, r^{-}} \operatorname{costs}^{r d}=\sum_{p, t}\left(g_{p, t}^{+} C_{p, t}\right)-\sum_{p, t}\left(g_{p, t}^{-} C_{p, t}\right)
$$

The re-dispatch model guarantees that line flows do not exceed the lines' maximum flow capacity $(\bar{P}$, eq. 6e). Changes in the output levels of power plants affect the network input $(n i)$ and the line flows $(p f)$, which are calculated using the linear approximation of the DC load flow approach (eqs. 6f, 6g, 6h). Generation output of conventional power plants can maximally be increased by the difference between the hourly available power plant capacity $(\bar{G})$ and the scheduled output level ( $g^{0}$, eq. 6a). The scheduled output level of the market dispatch can be decreased to zero (eq. $6 \mathrm{~b}$ ). The same holds for renewable plants $\left(r^{0}\right.$, eq. $\left.6 \mathrm{c}\right)$. At the same time the energy balance for the system must hold for each node (eq. 6d). Imports and exports to neighboring countries remain fixed to historic hourly cross-border flows. To decrease the complexity of the 
re-dispatch model, pumped-storage is fixed to the spot market dispatch and is not available for re-dispatch.

$$
\begin{aligned}
\text { s.t. } \quad g_{p, t}^{+} & \leq \bar{G}_{p, t}-g_{p, t}^{0} & & \forall p, t \\
g_{p, t}^{-} & \leq g_{p, t}^{0} & & \forall p, t \\
r_{n, s, t}^{-} & \leq r_{n, s, t}^{0} & & \\
\sum_{p \in n}\left(g_{p, t}^{0}+g_{p, t}^{+}-g_{p, t}^{-}\right)+\sum_{s}\left(r_{n, s, t}^{0}-r_{n, s, t}^{-}\right) & Q_{n, t} & & \\
+I M_{n, t}-E X_{n, t}+\sum_{e \in n} p s_{e, t}^{0}+n i_{n, t} & =0 & & \forall n, t \\
\left|p f_{l, t}\right| & \leq \bar{P}_{l} & & \forall l, t \\
n i_{n, t} & =\sum_{k}\left(\Theta_{k, t} B_{n, k}\right) & & \forall n, t \\
p f_{l, t} & =\sum_{n}\left(\Theta_{n, t} H_{l, n}\right) & & \forall l, t \\
\Theta_{n^{\text {slackbus }, t}} & =0 & & \forall t
\end{aligned}
$$

The models are implemented in the General Algebraic Modeling System (GAMS) version 24.2 and solved with the commercial solver CPLEX.

\subsection{Model data}

The methodology is applied to data from the German electricity sector of 2012, having a nodal spatial disaggregation (Egerer et al., 2014). The geocoded network topology consists of 438 network nodes and 938 transmission lines representing the high voltage transmission system of 220 and $380 \mathrm{kV}$. Information on individual conventional power plant blocks, renewable capacities, and electricity load is linked to the network nodes (figure 1). The hourly time series for 2012 include load, cross-border flows, as well as seasonal availability factors for conventional and regional hourly factors for renewable power plants. The model runs are conducted for the 8784 hours of 2012 in 53 weekly blocks. For reasons of simplicity, the import flows from and export flows to neighboring countries are fixed to the hourly physical flows observed on the cross-border lines in 2012. The limitation of the spatial scope to the German electricity system abstracts from the interactions with the electricity markets of neighboring countries.

The aggregation of the nodal data set to one energy balance for the single bidding area and two separate energy balances for one northern and one southern bidding area with a cross-zonal NTC provides the input data for the model runs. The annual demand of the northern zone (357 TWh per year) is significantly higher than in the southern zone (194 TWh per year). The hourly load varies between $36 \mathrm{GW}$ in off-peak and $86 \mathrm{GW}$ for peak load. In the zonal generation portfolios of 2012, proportionally higher shares exist for lignite, hard coal, and wind power in the northern zone compared to nuclear, hydropower, and solar PV in the southern zone (table 1). Between 2012 and 2015, the northern zone sees additional onshore and offshore wind investment. At the same time, several new hard coal plants (+5500 MW) started operation, resulting in an overall increase of $1200 \mathrm{MW}$, after having eliminated old coal capacities. In the south, one nuclear power plant is scheduled to be shut down in 2015. Half of this capacity is compensated by one new coal power plant and additional peak capacity (-1300 MW) retires. Solar PV is expected to exceed $40000 \mathrm{MW}(+9000 \mathrm{MW})$ with about equal shares for both zones. While the overall conventional capacity hardly changes, a shift of $2000 \mathrm{MW}$ takes place from the southern to the northern zone.

\footnotetext{
${ }^{13}$ Pumped-storage in southern Germany includes $1096 \mathrm{MW}$ in Luxemburg and $1503 \mathrm{MW}$ in Austria connected to the German system.
} 


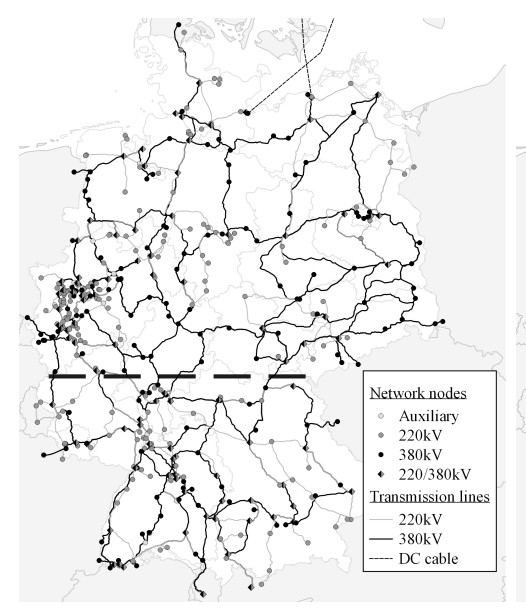

(a) Transmission network

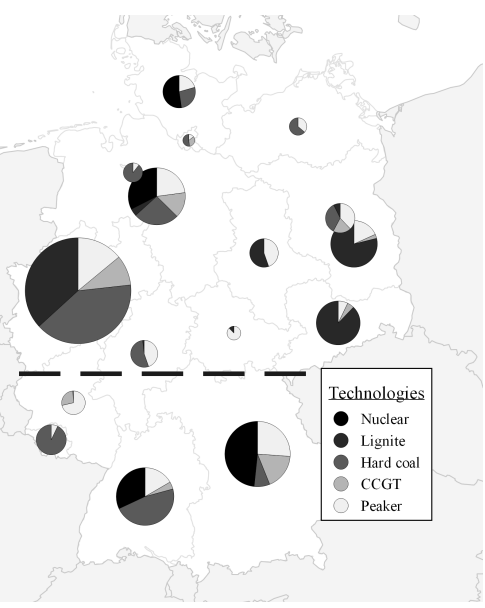

(b) Conventional capacities

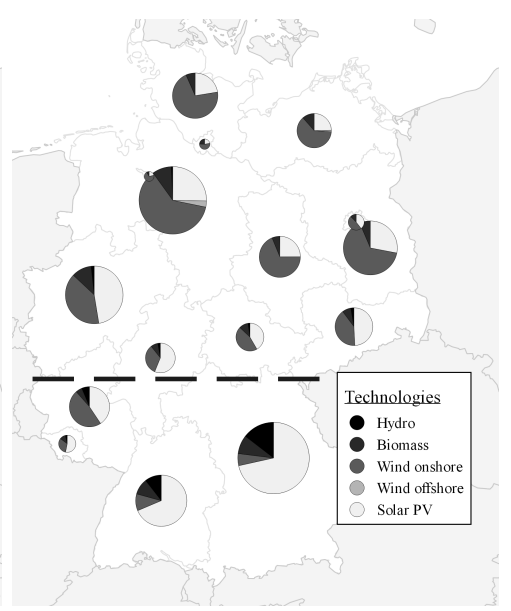

(c) Renewable capacities

Figure 1: Spatial electricity data for the German electricity sector in 2012

\begin{tabular}{l|rr|rr}
\hline$[\mathrm{MW}]$ & \multicolumn{2}{|c|}{$\mathbf{2 0 1 2}$} & \multicolumn{2}{c}{$\mathbf{2 0 1 5}$} \\
Technology & North & South & North & South \\
\hline Nuclear & 4099 & 7969 & & -1275 \\
Lignite & 20350 & - & +580 & \\
Hard coal & 17580 & 7090 & +1205 & +640 \\
CCGT & 5228 & 3231 & +1005 & \\
Gas & 8406 & 3939 & -1181 & -155 \\
Oil & 2145 & 1687 & -206 & -1196 \\
Waste & 1059 & 411 & & \\
Other & 2327 & 147 & -110 & \\
Pumped-storage ${ }^{13}$ & 3927 & 4862 & & \\
\hline Sum conventional & 65121 & 29336 & +1293 & -1986 \\
\hline Hydropower & 588 & 3124 & +16 & +84 \\
Biomass & 4326 & 2052 & +355 & +168 \\
Solar PV & 16800 & 15551 & +4687 & +4339 \\
Wind onshore & 28520 & 2964 & +5561 & +578 \\
Wind offshore & 388 & - & +2612 & \\
\hline Sum renewable & 50622 & 23691 & +13231 & +5169 \\
\hline Peak load in zones & 54640 & 31390 & & \\
\hline
\end{tabular}

Table 1: Generation capacities and peak load for 2012 and change in 2015

Compared to 2012, the increasing share of wind power and the regional shift in conventional capacity with low variable generation costs in 2015 is likely to increase the regional imbalance in the least cost generation dispatch for many hours. The scenarios for 2012 and 2015 reflect the German electricity system as discussed in the data section. One additional sensitivity on the 2015 results tests the effect of investment in the transmission infrastructure. It assumes that the transmission line Vieselbach-Altenfeld-Redwitz (two circuits of $380 \mathrm{kV}$ of north to south transmission capacity between eastern and southern Germany) and the Uckermarkleitung for better wind integration north-east of Berlin will become operational by 2015.

As mentioned above, the model simplifications are likely to overestimate the flexibility of the system and thus underestimate re-dispatch costs on the national level for 2012. The limitation of the model scope to the German system, fixing cross-border flows to 2012 values, abstracts from the market implications the alternative bidding zone configuration would have on neighboring electricity markets. 


\section{Results}

The result section distinguishes between effects two bidding zones have on the market dispatch (4.1), on re-dispatch levels (4.2), as well as on distributional implications (4.3). A sensitivity run for 2015 presents the effect of limited network investment enforcing the German transmission network (4.4).

\subsection{Implications of two bidding zones on the spot market dispatch}

The only additional market constraint of zonal pricing is the limitation for trade between the two bidding zones. The level of the NTC affects the spot market results. In hours of a binding constraint on trade, the market dispatch in the spot market replaces generation with lower variable costs in the northern bidding zone by more expensive generation capacity in the southern bidding zone. The market dispatch has a stronger zonal focus and decreased north to south transmission flows in the physical transmission network. Consequently, situations with line flows exceeding the capacity of individual lines between generation in the northern zone and load centers in the southern zone become less frequent and less severe.

The trade flows in the spot market are mostly directed from north to south while few summer hours have small reverse flows (figure 2). The seasonal characteristics of the trade flows show high electricity exchanges in many hours during the winter months when the NTC of $8000 \mathrm{MW}$ becomes binding and prices are higher in the south. The NTC from south to north is never binding in the spot market. Thus, implications of zonal pricing depend mostly on the load pattern during the winter (e.g. severe versus mild winter) and the respective hourly wind generation levels. The annual trade flows increase from $29.8 \mathrm{TWh}$ in 2012 to 40.7 TWh in 2015 (north to south) and decrease from 0.6 TWh in 2012 to 0.3 TWh in 2015 (south to north).

The implementation of NTCs between the two bidding zones affects the power plant dispatch in the spot market (table 2). In the southern zone output increases by about $0.5 \mathrm{TWh}$ in 2012 and $2.4 \mathrm{TWh}$ in 2015, while it decreases in the northern zone. The regional redistribution mostly affects hard coal and gas-fired power plants. The relative changes are smaller in the northern zone but reach $2 \% / 3 \%$ for hard coal-/gas-fired power plants in the southern zone in 2012 and about 4\%/10\% in 2015.

\begin{tabular}{l|rrrrrrr}
\hline [TWh per year] & \multicolumn{6}{|c}{ Producer } \\
& & Nuclear & Lignite & Coal & Gas & Other & EE \\
\hline \multirow{2}{*}{$\mathbf{2 0 1 2}$} & North & 32.4 & 142.6 & $(-0.4) 103.9$ & $(-0.1) 21.3$ & 18.8 & 88.1 \\
& South & 63.0 & - & $(+0.3) 39.5$ & $(+0.2) 14.0$ & 3.2 & 49.0 \\
\hline \multirow{2}{*}{$\mathbf{2 0 1 5}$} & North & 32.4 & $(-0.1) 145.7$ & $(-1.9) 99.8$ & $(-0.3) 12.6$ & 18.2 & 109.4 \\
& South & 52.9 & - & $(+1.6) 37.5$ & $(+0.8) 7.8$ & 3.2 & 55.9 \\
\hline
\end{tabular}

Table 2: Zonal generation levels for two price zones and change compared to one price zone

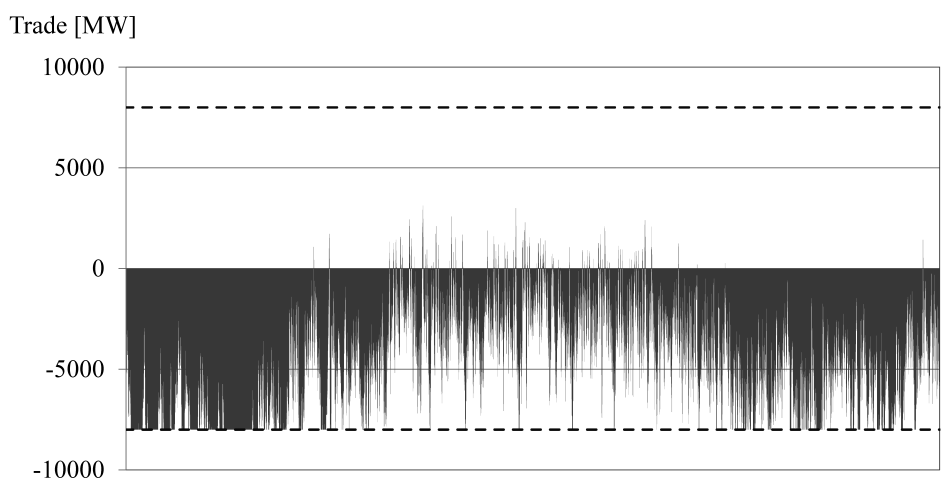

Figure 2: Hourly trade flows north to south (-) and south to north (+) over the year 2015 (Jan-Dec) 


\subsection{Implications of two bidding zones on re-dispatch}

Even though the zonal market dispatch has higher generation costs in the first place, it can reduce the amount of curative congestion management. Figure 3 illustrates the change in annual zonal re-dispatch levels for different NTC values in 2012 and 2015.

2012

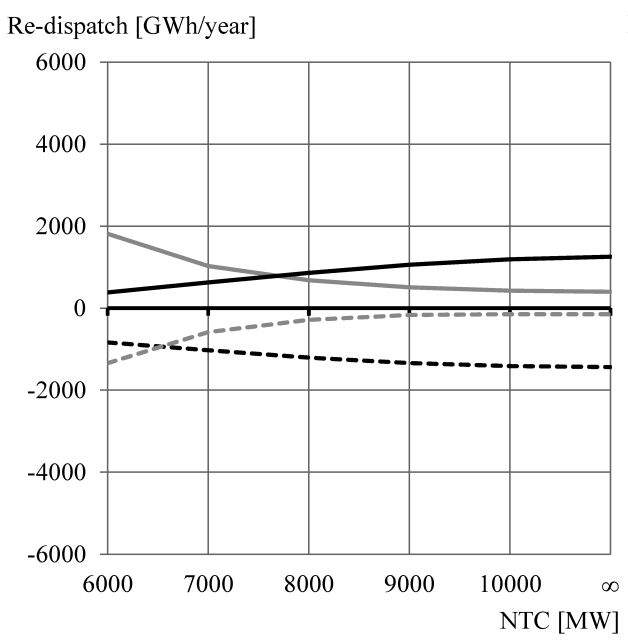

2015

Re-dispatch [GWh/year]

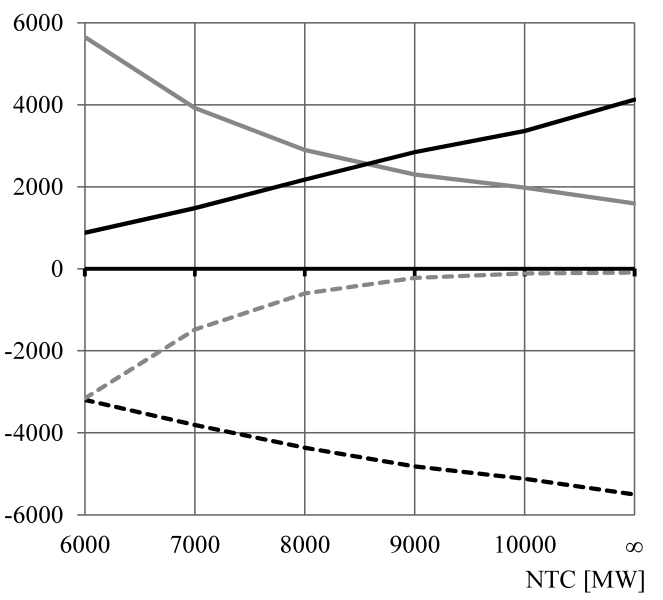

- North up --- North down

South up

--- South down

Figure 3: Re-dispatch for different NTC levels with up- and down-regulation in the two bidding zones

For very high NTCs, zonal pricing becomes ineffective as the dispatch in the spot market converges to the levels of the single bidding zone. In general, binding NTCs reduce the re-dispatch levels for shifting generation between the northern (lower down-regulation) and the southern zone (lower up-regulation). The cross-zonal re-dispatch continues to decline with lower NTC levels. However, lower capacities for trade in the spot market exclude increasing levels of generation in the northern bidding zone from the market that is not related to the congested lines in the physical transmission system. The excluded capacity is replaced in the market dispatch by more expensive generation in the southern bidding zone. Under the assumption of optimal (cost-minimizing) re-dispatch, the TSO reschedules this capacity in the north into the market (upregulation), replacing the more expensive generation capacity in the south (down-regulation). Re-dispatch opposite to the initially predominant north-south direction starts to increase. An additional aspect is the imbalance between down-regulation in the north and up-regulation in the south (and vice versa), indicating re-dispatch due regional structural differences within the northern bidding zone for lower NTCs.

In the model results for 2012 and 2015, the NTC of 8000 MW has the lowest re-dispatch levels. ${ }^{14}$ However, the implementation of two bidding zones only allows a limited reduction of overall re-dispatch. Levels decrease from $1655 \mathrm{GWh}$ per year for the single price zone to $1544 \mathrm{GWh}$ per year $(-7 \%)$ before they start to increase again for lower NTCs. ${ }^{15}$ In 2015 , the growing spatial system imbalance in the spot market dispatch is reflected in a threefold increase of re-dispatch. Zonal pricing allows a reduction from 5720 to 5071 GWh per year $(-11 \%) .{ }^{16}$ The main effects of zonal pricing are lower re-dispatch levels between the

\footnotetext{
${ }^{14}$ There might be factors deciding the NTC level other than the total re-dispatch level. Addressing all congestion and imbalances within each bidding zone by the cross-zonal trade capacity would result in significantly lower values for the NTC and higher re-dispatch levels within each zone. Other motivations for choosing NTC levels could be the maximization of congestion rents by the TSO or a preference on zonal price differentials to limit redistribution levels.

${ }^{15}$ The re-dispatch level induced by current in the German electricity system reached 1962 GWh in 2012 (BNetzA and Bundeskartellamt, 2014).

${ }^{16} \mathrm{An}$ additional option to improve the effect of two bidding zones is the sub-annual adjustment of the NTC level. Combining the weekly runs with the NTC value resulting in the lowest weekly re-dispatch levels - values vary between 6000 and 10000 MW - allows about $10 \%$ higher reductions for re-dispatch.
} 
bidding zones. In 2015, they decrease by about 35\%. In the south, re-dispatch measures remain mostly upwards, but levels decrease for coal-fired power plants by about $1500 \mathrm{GWh}$ and gas-fired power plants by about 500 GWh per year. Total downward re-dispatch in the southern zone increases only by about $500 \mathrm{GWh}$ per year (table 3, figure 4), reducing overall cross-zonal re-dispatch by almost $1500 \mathrm{GWh}$. In the northern bidding zone, up-regulation increases to about the same extent as down-regulation decreases for all conventional generation technologies. The results indicate that one northern and one southern bidding zone improves the regional market result. However, the two zones might not be capable of providing sufficiently differentiated price signals to solve the issue of increasing re-dispatch levels. In particular this seems to be the case for the northern bidding zone with its increasing internal re-dispatch level in 2015.

The spot market requires a limitation on the trading capacity to reduce re-dispatch between the two bidding zones. However, the zonal constraint does not just affect those power plants in the northern zone that are causing the network congestion. In the northern bidding zone, the most expensive generation capacities in the market dispatch of the single bidding zone are replaced in case of two bidding zones in hours of binding NTCs. It is mostly the hard coal power plants in the western regions of the northern bidding zone that are affected. These plants have higher fuel costs than comparable coal power plants located closer to the coast due to higher coal shipment costs. Yet, their impact on the major bottlenecks in the transmission network - i.e. lines for wind integration in the north and most important the corridor between eastern and southern Germany - is limited. The two bidding zones also affect the generation output of hard coal plants at the coast for low load and/or high wind feed-in. In the eastern part - a region with frequent oversupply - the most expensive technology in the market (i.e. lignite) is rarely affected by the two bidding zones, as its variable costs are lower than for most other fossil technologies in the northern bidding zone.

The TSO mostly uses hard coal plants and some gas capacities in western Germany, which are often excluded from the spot market dispatch at zonal pricing for the re-dispatch to create a technically feasible generation dispatch. They are followed by more expensive generation capacity in the south. Replaced are both (i) hard coal capacities close to the North and Baltic Seas (even though with slightly decreasing levels at zonal pricing), causing network problems in hours of high wind generation in the coastal region, and (ii) lignite generation in eastern Germany, creating - together with wind generation - severe congestion on lines between eastern and southern Germany. These effects of two bidding zones result in overall lower re-dispatch than for the single bidding zone. The decrease in up-regulation in the southern zone and downregulation in the northern zone is higher than increase of the counter-wise effects (figure 4).

\begin{tabular}{rl|rrr|rrr}
\hline [GWh per year] & \multicolumn{3}{|c|}{ Uniform pricing } & \multicolumn{3}{c}{ Zonal pricing } \\
& & Lignite & Coal & Gas & Lignite & Coal & Gas \\
\hline \multirow{2}{*}{2012} & North & $+38 /-129$ & $+146 /-1078$ & $+215 /-229$ & $+40 /-119$ & $+397 /-907$ & $+244 /-180$ \\
& South & - & $+819 /-75$ & $+432 /-72$ & - & $+589 /-109$ & $+272 /-176$ \\
\hline \multirow{2}{*}{$\mathbf{2 0 1 5}$} & North & $+407 /-1882$ & $+658 /-2980$ & $+529 /-642$ & $+520 /-1770$ & $+1662 /-2117$ & $+714 /-475$ \\
& South & - & $+3014 /-59$ & $+1111 /-33$ & - & $+1577 /-246$ & $+597 /-355$ \\
\hline
\end{tabular}

Table 3: Zonal re-dispatch levels per technology 


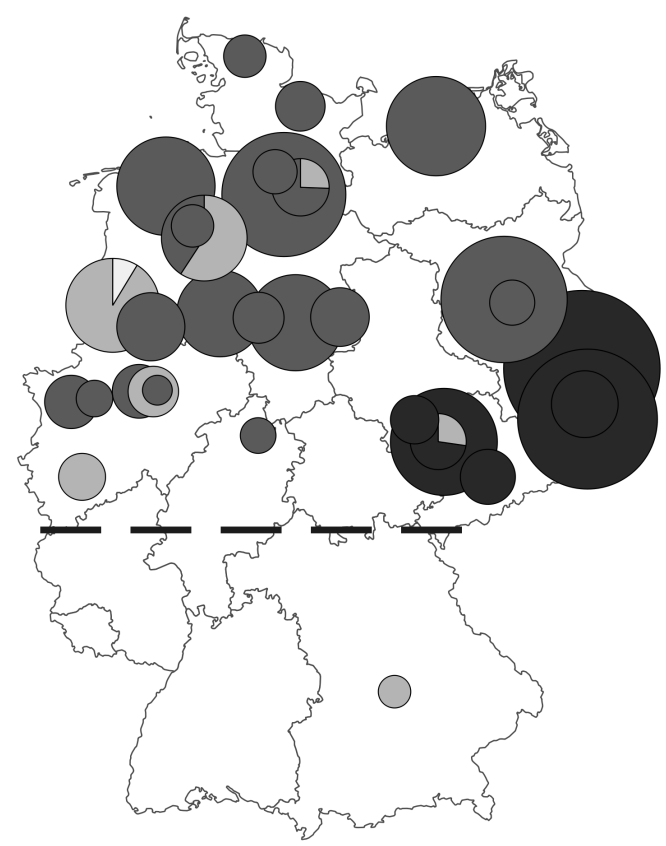

(a) Down-regulation single price zone

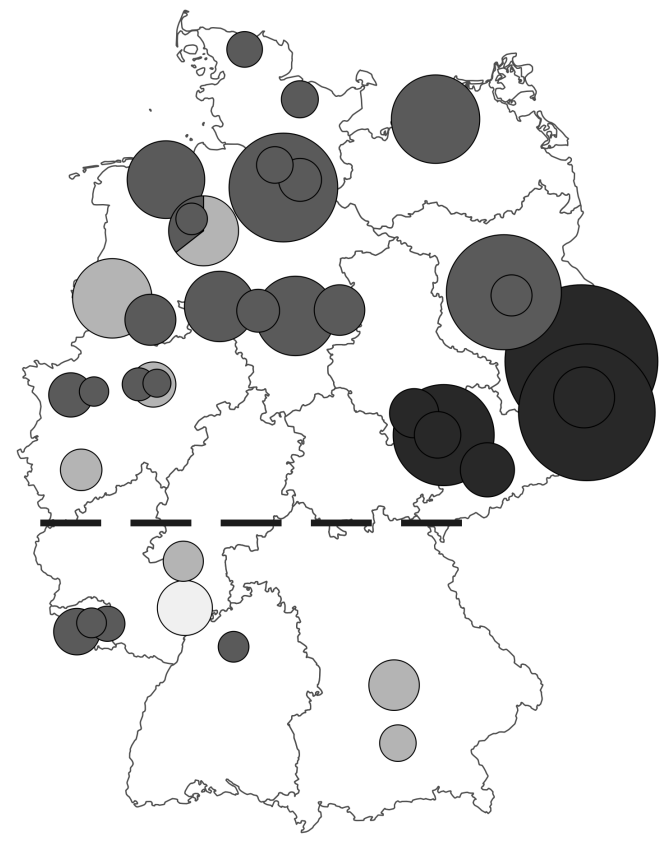

(c) Down-regulation two price zones

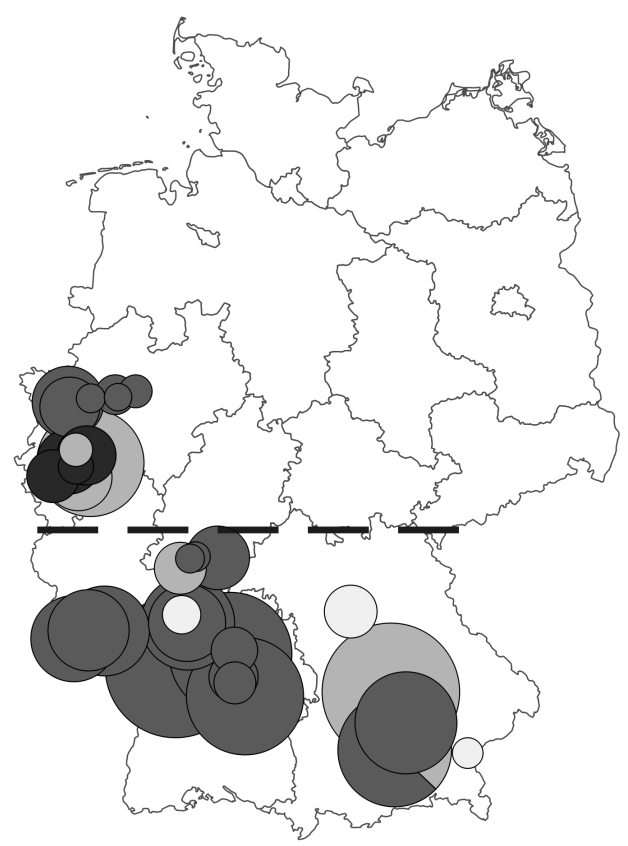

(b) Up-regulation single price zone

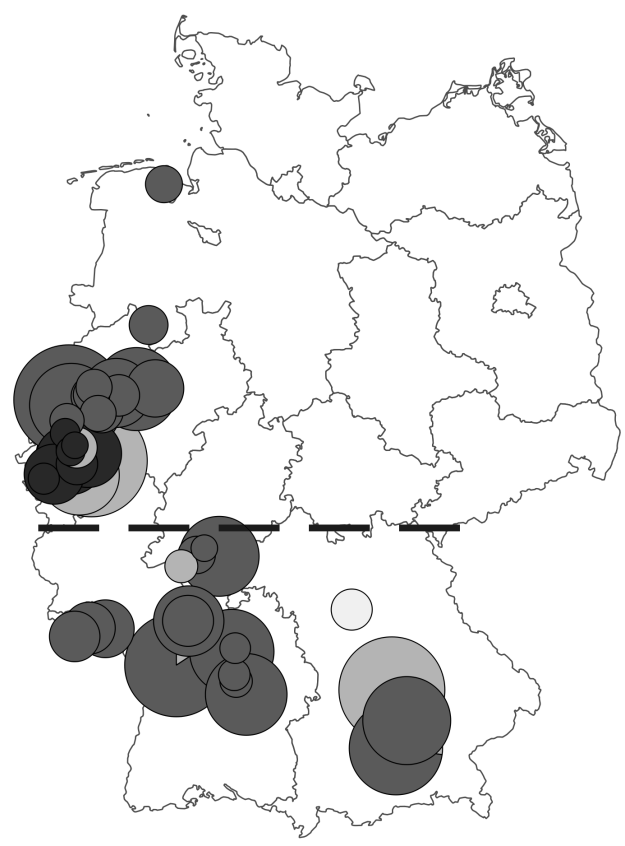

(d) Up-regulation two price zones

- Lignite $\bigcirc$ Hard coal $\bigcirc$ CCGT $\bigcirc$ Peaker

Figure 4: Re-dispatch in 2015 for the single and two price zones 


\subsection{Distributional implications}

As known from the literature, shifts in the regional pricing scheme, either by re-shaping market zones or changing cross-zonal trade capacity affects market prices, creating winners and losers. In the model results, the average annual electricity price differential between the bidding zones of $0.4 \mathrm{EUR} / \mathrm{MWh}$ in 2012 is rather low but grows to $1.7 \mathrm{EUR} / \mathrm{MWh}$ in $2015 .{ }^{17}$ Compared to the single price zone, increases in the south are about three times higher than the opposite decreases in the north. Zonal prices deviate in about 450 hours in 2012 with a maximum difference of $33.6 \mathrm{EUR} / \mathrm{MWh}$ and an average difference of 6.9 EUR/MWh. Many hours with a significant price difference occur in January and February, arise at a price level of about $50 \mathrm{EUR} / \mathrm{MWh}$, with deviating zonal prices more frequent in hours with high wind power generation (figure 6). Hours with a high residual load in the southern zone are more likely to result in high price differentials. The opposite causality holds for the northern zone to a smaller extent.

The results for 2015 reflect the growing regional imbalance in generation capacity of low variable costs both for wind turbines and conventional power plants. Zonal prices deviate in 1455 hours of the year with a maximum difference of $50.5 \mathrm{EUR} / \mathrm{MWh}$ and an average difference of $10.2 \mathrm{EUR} / \mathrm{MWh}$. The number of hours with a difference in zonal prices increases in situations where coal sets the marginal price in the northern zone (i.e. at about 40-50 EUR/MWh) as well as with high wind generation (levels above $28000 \mathrm{MW}$ always result in a price differential).

In the case of two bidding zones for Germany, the implications on different stakeholders of one zone (i.e. consumers and producers of different technologies) are the same in 2012 and 2015. Yet, the level of redistribution increases by the same magnitude as does the price differential. Consumers benefit from lower prices in the north while producer rents decrease and vice versa with increasing prices in the south (table 4). In 2012, the total redistribution between consumers and producers is limited to about $50 \mathrm{mn}$ EUR per year in both zones. In 2015, distributional effects increase, as consumers see their payments increase by $275 \mathrm{mn}$ EUR per year in the south and a reduction of $163 \mathrm{mn}$ EUR per year in the north.

At the same time redistribution for generation increases to about $200 \mathrm{mn}$ EUR per year. In the north, renewables (-79 mn EUR per year), followed by lignite (-66 mn EUR per year), hard coal (-39 mn EUR per year), and nuclear plants (-15 mn EUR per year) are the generation technologies that lose the most profits in 2015. On the contrary, in the south, nuclear $(+74 \mathrm{mn}$ EUR per year), renewables $(+57 \mathrm{mn}$ EUR per year), hard coal (+55 mn EUR per year), and CCGT plants (+13 mn EUR per year) are the biggest profiteers.

The auctioning of trade capacity in the spot market provides scarcity rents to the TSO, increasing from $25 \mathrm{mn}$ EUR per year in 2012 to $119 \mathrm{mn}$ EUR per year in $2015 .{ }^{18}$

Breaking down the total redistribution (table 4) to values per MWh (table 5) provides insights in the interdependency of price deviations with load and generation. Consumers in the south pay a higher than average zonal price mark-up due to additional zonal scarcity in hours of high load. ${ }^{19}$ In the north, their price reduction is in line with the average price decrease.

Similar patterns can be observed on the supply side with the difference that generation benefits from lower price decreases in the north and higher mark-ups in the south. Results are driven by two factors: (i) exogenous seasonable availability factors are higher in the winter than in the summer months and (ii) generation technologies with higher variable costs operate mostly in hours of increased scarcity when prices tend to increase more in the south and decrease less in the north. The seasonal effect explains the results for technologies operating at full capacity in most hours, i.e. nuclear and lignite. Hard coal and, in particular, gas-fired power plants in the south benefit additionally from the regional scarcity signals, i.e. higher prices in the southern zone in 2015. Finally, the merit order effect of renewable generation increases with two

\footnotetext{
${ }^{17}$ Due to the model assumptions the zonal price difference could be underestimated. (Thema, 2013) predicts in a market study on two price zones in Germany a price differential of 3.8 EUR/MWh for an NTC of 7000 MW in 2012, which decreases to $1.5 \mathrm{EUR} / \mathrm{MWh}$ for $10000 \mathrm{MW}$.

${ }^{18}$ Zonal pricing also affects payments for import and export flows with neighboring countries. The results are not discussed in this paper as neighboring markets are not modeled endogenously.

${ }^{19}$ The change in consumer rents is calculated by the hourly change in electricity prices between the single and two price zones multiplied by the hourly zonal load.
} 
bidding zones. Consequently, mark-ups are lower in the south and price declines higher in the north for renewable feed-in.

\begin{tabular}{ll|r|r|r|r|r}
\hline [mn EUR per year] & $\begin{array}{r}\text { Consumer } \\
\text { rents }\end{array}$ & \multicolumn{2}{|c|}{$\begin{array}{c}\text { Producer profits } \\
\text { Conventional }\end{array}$} & $\begin{array}{c}\text { Costs } \\
\text { Renewables }\end{array}$ & $\begin{array}{c}\text { Congestion } \\
\text { im-/exports }\end{array}$ \\
\hline \multirow{2}{*}{$\mathbf{2 0 1 2}$} & North & +35.2 & -30.4 & -16.2 & +2.0 & +25.0 \\
& South & -58.4 & +36.0 & +10.9 & -8.3 & +18.3 \\
\hline \multirow{2}{*}{$\mathbf{2 0 1 5}$} & North & +163.4 & -127.0 & -78.9 & +32.7 & +118.5 \\
& South & -274.6 & +149.3 & +57.0 & -32 \\
\hline
\end{tabular}

Table 4: Change in payments and rents for two bidding zones

\begin{tabular}{ll|r|r|rrrrr}
\hline \multicolumn{2}{c|}{ [EUR/MWh] } & Price & Consumer & \multicolumn{6}{|c}{ Producer } \\
& & & Nuclear & Lignite & Coal & Gas & RES \\
\hline \multirow{2}{*}{2012} & North & -0.10 & -0.10 & -0.10 & -0.10 & -0.10 & -0.04 & -0.18 \\
& South & +0.26 & +0.30 & +0.29 & - & +0.33 & +0.28 & +0.22 \\
\hline \multirow{2}{*}{2015} & North & -0.46 & -0.46 & -0.47 & -0.45 & -0.40 & -0.30 & -0.72 \\
& South & +1.22 & +1.41 & +1.40 & - & +1.47 & +2.20 & +1.02 \\
\hline
\end{tabular}

Table 5: Change in prices, cost for consumers, and profits for producers for two price zones

\subsection{Scenario with network extension in 2015}

The scenario with network extensions includes one major line investment between the northern and southern bidding zone. The Vieselbach-Altenfeld-Redwitz line provides additional transmission capacity parallel to the link that causes the greatest re-dispatch levels in the model results. Overall re-dispatch levels decrease from 5720 to $4094 \mathrm{GWh}$ per year, but remain at twice the level of 2012. For the single price zone (represented by an unlimited NTC in figure 5), the entire reduction of re-dispatch with the additional lines (about $1600 \mathrm{GWh}$ per year) is between the northern and southern bidding zone.

For the two bidding zones the NTC value with lowest re-dispatch increases to $10000 \mathrm{MW}$. Re-dispatch reduces to $3850 \mathrm{GWh}$ per year $(-6 \%)$ and the remaining levels are shared almost evenly on reallocation between the northern and southern zone and internal measures within the northern zone. Thus, the importance of the two bidding zones on network congestion and re-dispatch levels decreases. The price difference is reduced to $0.4 \mathrm{EUR} / \mathrm{MWh}$. Price differentials occur in 556 hours per year with a maximum price difference of 26.2 EUR/MWh and an average price difference of 5.7 EUR/MWh. Distributional effects are in the range of the 2012 results. ${ }^{20}$

\footnotetext{
${ }^{20}$ Due to the high level of re-dispatch remaining for two bidding zones an alternative zonal setting could improve the results. For two bidding zones the western part of the northern zone could be added to the south focusing more on excess generation (lignite, hard coal, and wind) instead of on the scarcity in southern Germany. The existing research on clustering electricity markets to an optimal bidding zone configurations so far does not provide transparent and fair criteria to determine stable bidding zones.
} 

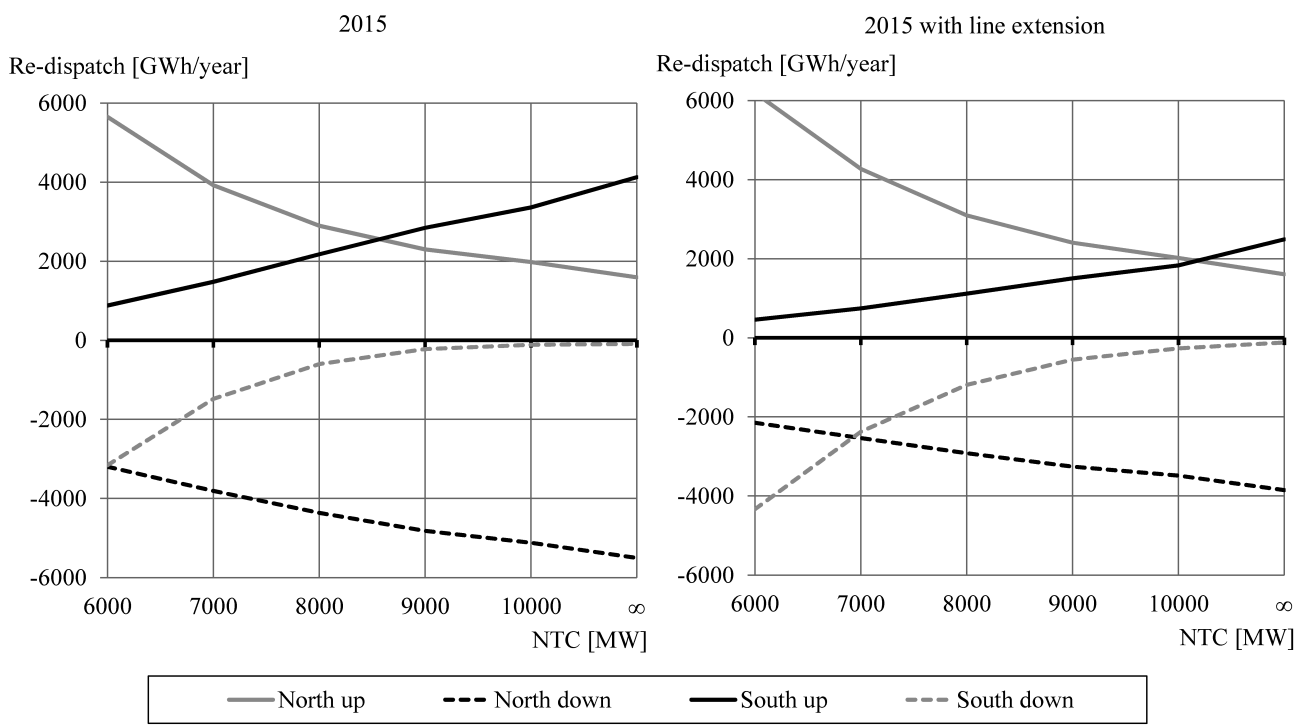

Figure 5: Implication of line extension on zonal re-dispatch

\section{Conclusion}

This paper analyzes some potential effects of the creation of two bidding zones for the German electricity market in 2012 and 2015: one northern and one southern bidding zone. An additional scenario with network extension in 2015 is also considered. The existing single bidding zone in the German electricity market does not reflect regional imbalances and the transmission network in the market dispatch. The concentration of fossil generation capacity with comparably low variable costs - not internalizing all external costs - and wind power in the northern and eastern parts of Germany combined with limited north-south transmission capacity causes an increasing amount of curative congestion management measures. For Germany's presentday single price area the model results of this paper predict a threefold increase of re-dispatch levels over the course of expected changes of generation capacities from 2012 to 2015. In the network perspective, the internal congestion can be addressed by transmission investment to strengthen the north-south connections. Investment in the transmission network has been facilitated in Germany with legislation in 2009 and the network development plans starting in 2012. Still, investments in transmission lines take many years to realize and their prospects are uncertain. To reduce re-dispatch measures, scarce transmission capacity can also be addressed by pricing it into the electricity market.

For the case of two price zones in Germany, model results indicate slightly declining re-dispatch levels, in particular between the bidding zones. In hours of strong regional imbalances, one observes price differences at significant levels, which could set regional incentives for investment in supply and demand in the longterm, an aspect not elaborated on in this paper. One important consideration when moving from one pricing scheme to another are distributional implications for stakeholders. Predicted differences in average electricity prices between the two bidding zones are rather low in the model results (1.7 EUR/MWh in 2015) compared to the wholesale price and network charges. However, stakeholders benefit and lose in different ways. Total figures of redistribution between consumers and producers in the northern and southern zones amount to several hundred million Euros per year. These numbers could make it challenging to communicate the effects to the stakeholders, especially at the Federal State level. Additional system and distributional implications with neighboring countries - price zones change the import and export patterns - are not addressed in this paper. In case of high wind feed-in in northern Germany, a lower electricity price in the northern zone could reduce imports into and exports from the zone. Hours with scarcity and higher prices in southern Germany could reduce exports to southern Europe. These effects may be important in the context of the European discussion on bidding zones and require further research. 
The results of this paper indicate that additional bidding zones in Germany might not be necessary in the short-term. However, regional imbalances will continue to increase as new wind capacity becomes operational in northern Germany and the nuclear phase-out takes place by 2022, creating additional scarcities in southern Germany. Regardless of network extension, additional research should analyze the implications of different approaches to regional pricing in an electricity sector increasingly dominated by renewable generation.

\section{Acknowledgements}

This work was carried out as a part of the projects "MASMIE - Model-based analyses to design the energy market for the integration of renewable energy sources within the framework of the energy transition" and "EE-Netz - Reformbedarf und -modelle für den effizienten Ausbau und Betrieb der Elektrizitätsnetze im Rahmen der Energiewende", both supported by Stiftung Mercator. The authors would like to thank Friedrich Kunz, Charlotte Loreck, Clemens Gerbaulet, Alexander Weber, Christian von Hirschhausen, as well as participants and reviewers of IEWT 2015 Conference, IAEE 2014 European Energy Conference, YEEES 2014 Spring Seminar, and DIW Sustainability Cluster Seminar for comments and reviews of earlier versions. The usual disclaimer applies. 


\begin{tabular}{|c|c|c|}
\hline & Unit & Description \\
\hline \multicolumn{3}{|c|}{ Indices and Sets } \\
\hline \multicolumn{2}{|c|}{$e \in E$} & Pumped-storage hydropower stations \\
\hline \multicolumn{2}{|l|}{$l \in L$} & Transmission lines in the network \\
\hline \multicolumn{2}{|l|}{$n, k \in N$} & Nodes in the network \\
\hline \multicolumn{2}{|l|}{$p \in P$} & Power plant blocks \\
\hline \multirow{2}{*}{\multicolumn{2}{|c|}{$\begin{array}{l}s \in S \\
t \in T\end{array}$}} & Renewable technologies \\
\hline & & Hours \\
\hline \multicolumn{2}{|l|}{$z, y \in Z$} & Price zones \\
\hline \multicolumn{3}{|c|}{ Parameters } \\
\hline \multicolumn{3}{|r|}{ Network susceptance matrix } \\
\hline \multirow{2}{*}{$\begin{array}{l}C_{p, t} \\
E X_{n, t}\end{array}$} & EUR/MWh & Variable generation costs \\
\hline & MW & Cross-border export flow \\
\hline $\bar{G}_{p, t}$ & MW & Maximum conventional generation capacity \\
\hline \multirow{2}{*}{$\begin{array}{l}g_{p, t}^{0}, \\
H_{l n}\end{array}$} & MW & Result for conventional generation in spot market model \\
\hline & $1 / \Omega$ & Network transfer matrix \\
\hline$I M_{n, t}$ & MW & Cross-border import flow \\
\hline$\overline{L S}_{e}$ & MWh & Maximum energy storage of pumped-storage plant \\
\hline$\overline{N T C}_{z, y}$ & MW & Maximum net transfer capacity (NTC) \\
\hline \multirow{2}{*}{$\frac{\bar{P}_{l}}{P S_{e}}$} & MW & Maximum power flow on transmission line \\
\hline & MW & Maximum turbine capacity of pumped-storage plant \\
\hline$p s_{e, t}^{0}$ & MW & Result for pumped-storage operation in spot market model \\
\hline \multirow{2}{*}{$\begin{array}{l}Q_{n, t} \\
R_{n, s, t}\end{array}$} & MW & Electricity load \\
\hline & MW & Maximum renewable generation capacity \\
\hline \multirow{2}{*}{$\begin{array}{l}r_{n, s, t}^{0} \\
\text { Variables }\end{array}$} & MW & Result for renewable generation in spot market model \\
\hline & \multicolumn{2}{|c|}{ Variables } \\
\hline \multirow{2}{*}{$\begin{array}{l}\operatorname{costs}^{r d} \\
\operatorname{costs}^{s p}\end{array}$} & EUR & Re-dispatch costs of the re-dispatch model \\
\hline & EUR & Dispatch costs of the spot market model \\
\hline$\Theta_{n, t}$ & & Phase angle difference in respect to slack bus \\
\hline$n i_{n, t}$ & MW & Net grid input \\
\hline \multirow{2}{*}{$\begin{array}{l}p f_{l, t} \\
p z_{z}\end{array}$} & MW & Power flow \\
\hline & MW & Cross-zonal trade flows in spot market model \\
\hline \multicolumn{3}{|c|}{ Positive Variables } \\
\hline$g_{p, t}$ & MW & Conventional generation in spot market model \\
\hline$g_{p, t}^{+}$ & MW & Ramped up conventional generation in re-dispatch model \\
\hline$g_{p, t}^{-}$ & MW & Ramped down conventional generation in re-dispatch model \\
\hline $\overrightarrow{p s}_{e, t}$ & MW & Pumped-storage generation in spot market model \\
\hline$\overleftarrow{p s}_{e, t}$ & MW & Pumped-storage pumping in spot market model \\
\hline pslevel $_{e, t}$ & MWh & Pumped-storage energy content in spot market model \\
\hline$r_{n, s, t}$ & MW & Renewable generation in spot market model \\
\hline$r_{n, s, t}^{-}$ & MW & Ramped down renewable generation in re-dispatch model \\
\hline
\end{tabular}

Table 6: Nomenclature 


\section{Appendix 2: Additional Figures on Results}
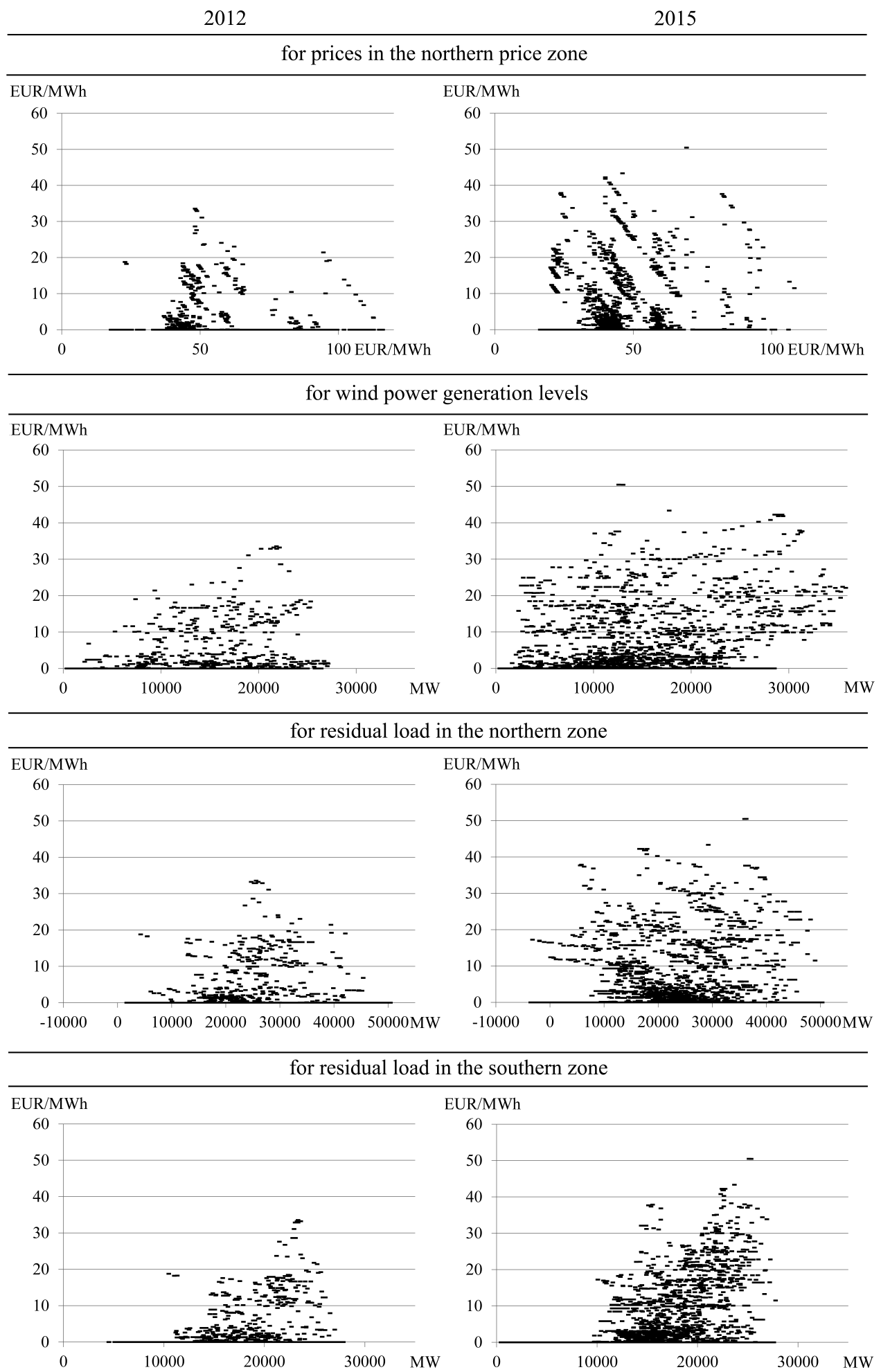

Figure 6: Price increase in the southern bidding zone compared to the northern zone 


\section{References}

50Hertz, Amprion, TenneT, and TransnetBW (2012): Netzentwicklungsplan 2012. 2. Entwurf.

ACER (2014): Report on the influence of existing bidding zones on electricity markets.

AG Energiebilanzen e. V. (2013): Energieverbrauch in Deutschland im Jahr 2012.

Bettzüge, M. O. (2014): Irreführende Annahme - Marc Oliver Bettzüge schlägt vor, zwei Preiszonen für Strom in Deutschland zu schaffen (Gastkommentar). Handelsblatt.

Bjørndal, M. and Jørnsten, K. (2001): Zonal Pricing in a Deregulated Electricity Market. The Energy Journal, $22(1)$ : 51-73. http://dx.doi.org/10.5547/ISSN0195-6574-EJ-Vol22-No1-3.

Bjørndal, M., Jørnsten, K., and Pignon, V. (2003): Congestion Management in the Nordic Power Market - Counter Purchases and Zonal Pricing. Journal of Network Industries, 4(3): 271-292.

BMWi (2014): Ein Strommarkt für die Energiewende.

BNetzA (2010): Monitoringbericht 2010.

BNetzA and Bundeskartellamt (2014): Monitoringbericht 2013.

Breuer, C., Echternacht, D., Linnemann, C., and Moser, A. (2011): Technical and economic comparison of national and joint cross-border curative congestion management application. 8th International Conference on the European Energy Market (EEM), 33-38. IEEE. http://dx.doi.org/10.1109/EEM.2011.5952974.

Breuer, C. and Moser, A. (2014): Optimized bidding area delimitations and their impact on electricity markets and congestion management. 11th International Conference on the European Energy Market (EEM), 1-5. IEEE. http://dx.doi.org/10. 1109/EEM.2014.6861218.

Breuer, C., Seeger, N., and Moser, A. (2013): Determination of alternative bidding areas based on a full nodal pricing approach. Power and Energy Society General Meeting (PES), 1-5. IEEE. http://dx.doi.org/10.1109/PESMG.2013.6672466.

Brunekreeft, G., Neuhoff, K., and Newbery, D. M. (2005): Electricity transmission: An overview of the current debate. Utilities Policy, 13(2): 73-93. http://dx.doi.org/10.1016/j.jup.2004.12.002.

Burstedde, B. (2012): From nodal to zonal pricing: A bottom-up approach to the second-best. 9th International Conference on the European Energy Market (EEM), 1-8. http://dx.doi.org/10.1109/EEM.2012.6254665.

Chaves-Ávila, J. P., van der Veen, R. A., and Hakvoort, R. A. (2014): The interplay between imbalance pricing mechanisms and network congestions - Analysis of the German electricity market. Utilities Policy, 28: 52-61. http://dx.doi.org/10. 1016/j.jup.2013.11.005.

Ding, F. and Fuller, J. (2005): Nodal, uniform, or zonal pricing: distribution of economic surplus. IEEE Transactions on Power Systems, 20(2): 875-882. http://dx.doi.org/10.1109/TPWRS.2005.846042.

Egerer, J., Gerbaulet, C., Ihlenburg, R., Kunz, F., Reinhard, B., Hirschhausen, C. v., Weber, A., and Weibezahn, J. (2014): Electricity Sector Data for Policy-Relevant Modeling: Data Documentation and Applications to the German and European Electricity Markets.

Ehrenmann, A. and Smeers, Y. (2005): Inefficiencies in European congestion management proposals. Utilities Policy, 13(2): 135-152. http://dx.doi.org/10.1016/j.jup.2004.12.007.

ČEPS, MAVIR, PSE, and SEPS (2012): Position of ČEPS, MAVIR, PSE Operator and SEPS regarding the issue of Bidding Zones Definition.

European Commission (1996): Directive 96/92/EC of the European Parliament and of the Council of 19 December 1996 concerning common rules for the internal market in electricity.

European Commission (2003): Directive 2003/54/EC of the European Parliament and of the Council of 26 June 2003 concerning common rules for the internal market in electricity and repealing Directive 96/92/EC.

European Commission (2009): Directive 2009/72/EC of the European Parliament and of the Council of 13 July 2009 concerning common rules for the internal market in electricity and repealing Directive 2003/54/EC.

European Commission (2014): Draft: Commission Regulation (EU) establishing a Guideline on Capacity Allocation and Congestion Management.

Frontier Economics and Consentec (2011): Bedeutung von etablierten nationalen Gebotszonen für die Integration des europäischen Strommarkts - ein Ansatz zur wohlfahrtsorientierten Beurteilung.

Frontier Economics and Consentec (2013): Bidding zone configuration.

Green, R. (1997): Electricity transmission pricing: an international comparison. Utilities Policy, 6(3): 177-184. http://dx.doi. org/10.1016/S0957-1787(97)00022-2.

Hogan, W. W. (1992): Contract Networks for Electric Power Transmission: Technical Reference.

Hogan, W. W. (1997): The Visible Hand in Electricity: Using a Pool to Expand Customer Choice or the ISO: "How Not to Get it Wrong". Restructuring '97 Conference. Amelia Island, FL.

Hogan, W. W. (1999): Transmission Congestion: The Nodal-Zonal Debate Revisited.

Hogan, W. W. (2014): Electricity Market Design and Efficient Pricing: Applications for New England and Beyond. The Electricity Journal, 27(7): 23-49. http://dx.doi.org/10.1016/j.tej.2014.07.009.

Holmberg, P. and Lazarczyk, E. (2015): Congestion Management in Electricity Networks: Nodal, Zonal and Discriminatory Pricing. The Energy Journal, 36(2): 145-166. http://dx.doi.org/10.5547/01956574.36.2.7.

Kunz, F. (2013): Improving Congestion Management: How to Facilitate the Integration of Renewable Generation in Germany. The Energy Journal, 34(4): 55-78. http://dx.doi.org/10.5547/01956574.34.4.4.

Kunz, F., Gerbaulet, C., and Hirschhausen, C. v. (2013): Mittelfristige Strombedarfsdeckung durch Kraftwerke und Netze nicht gefährdet. DIW Wochenbericht, 48.

Leuthold, F., Weigt, H., and Hirschhausen, C. v. (2012): A Large-Scale Spatial Optimization Model of the European Electricity Market. Networks and Spatial Economics, 12(1): 75-107. http://dx.doi.org/10.1007/s11067-010-9148-1. 
Löschel, A., Flues, F., Pothen, F., and Massier, P. (2013): Den Strommarkt an die Wirklichkeit anpassen: Skizze einer neuen Marktordnung.

Monopolkommission (2011): Sondergutachten 59: Strom und Gas 2011: Wettbewerbsentwicklung mit Licht und Schatten.

Neuhoff, K., Barquin, J., Bialek, J. W., Boyd, R., Dent, C. J., Echavarren, F., Grau, T., Hirschhausen, C. v., Hobbs, B. F., Kunz, F., Nabe, C., Papaefthymiou, G., Weber, C., and Weigt, H. (2013): Renewable electric energy integration: Quantifying the value of design of markets for international transmission capacity. Energy Economics, 40: 760-772. http://dx.doi.org/10.1016/j.eneco.2013.09.004.

Neuhoff, K., Hobbs, B. F., and Newbery, D. M. (2011): Congestion Management in European Power Networks: Criteria to Assess the Available Options. SSRN Scholarly Paper ID 1945704, Social Science Research Network, Rochester, NY. http://dx.doi.org/10.2139/ssrn.1945704.

Nüßler, A. (2012): Congestion and redispatch in Germany: a model-based analysis of the development of redispatch. Oldenbourg-Industrieverl., München.

Oggioni, G. and Smeers, Y. (2013): Market failures of Market Coupling and counter-trading in Europe: An illustrative model based discussion. Energy Economics, 35: 74-87. http://dx.doi.org/10.1016/j.eneco.2011.11.018.

Rubio-Oderiz, F. and Perez-Arriaga, I. (2000): Marginal pricing of transmission services: a comparative analysis of network cost allocation methods. IEEE Transactions on Power Systems, 15(1): 448-454. http://dx.doi.org/10.1109/59.852158.

Schweppe, F. C., Caramanis, R. D., Tabors, M. C., and Bohn, R. E. (1988): Spot Pricing of Electricity. Kluwer, Boston.

Stoft, S. (1996): Analysis of the California WEPEX Applications to FERC.

Stoft, S. (1997): Transmission pricing zones: simple or complex? The Electricity Journal, 10(1): 24-31. http://dx.doi.org/10. 1016/S1040-6190(97)80294-1.

Strbac, G., Pollitt, M., Konstantinidis, C. V., Konstantelos, I., Moreno, R., Newbery, D. M., and Green, R. (2014): Electricity transmission arrangements in Great Britain: Time for change? Energy Policy, 73: 298-311. http://dx.doi.org/10.1016/j. enpol.2014.06.014.

Supponen, M. (2011): Influence of national and company interests on European electricity transmission investments. Ph.D. thesis, Aalto University, Espoo.

Thema (2013): Loop flows - Final advice.

Trepper, K., Bucksteeg, M., and Weber, C. (2013): An Integrated Approach to Model Redispatch and to Assess Potential Benefits from Market Splitting in Germany. SSRN Scholarly Paper ID 2359328, Social Science Research Network, Rochester, NY. http://dx.doi.org/10.2139/ssrn.2359328.

Wawer, T. (2007): Konzepte für ein nationales Engpassmanagement im deutschen Übertragungsnetz. Zeitschrift für Energiewirtschaft, 31(2): 109-116.

Weigt, H., Jeske, T., Leuthold, F., and Hirschhausen, C. v. (2010): "Take the long way down": Integration of large-scale North Sea wind using HVDC transmission. Energy Policy, 38(7): 3164-3173. http://dx.doi.org/10.1016/j.enpol.2009.07.041.

Wissenschaftlicher Beirat BMWi (2014): Engpassbasierte Nutzerfinanzierung und Infrastrukturinvestitionen in Netzsektoren. 